\title{
A systematic review of brain imaging studies of semantic priming
}

\author{
Candice Steffen Holderbaum \\ Juliana Burges Sbicigo \\ Augusto Buchweitz \\ Jerusa Fumagalli de Salles
}

\begin{abstract}
The present systematic review aims to address the contribution of brain imaging studies to the investigation of semantic priming (SP). Only studies from 2001 to 2017 using lexical decision tasks with visual and auditory stimuli, were considered. The review resulted in 20 articles, which showed semantic priming effects (SPE) in several brain areas (frontal and temporal lobes, cingulate gyrus, supplementary motor areas, and parietal cortex). In this way, the identification of activation in these areas varied as a function of stimulus onset asynchrony (SOA). Data suggests both hemispheres are involved on SPE, with a more robust role of the left hemisphere. Specifically, a decreased activation on the left middle temporal gyrus was found to be related to automatic SPE. This same area seemed to be related to SPE at long SOAs, along with the left inferior frontal gyrus and the anterior cingulated cortex. Therefore, a strong performance of the left hemisphere in semantic priming tasks could be observed, especially in the left middle temporal gyrus. Its activation was modulated by short and long intervals between stimuli, with more activation associated with longer intervals.
\end{abstract}

Keywords: fMRl; semantic priming; lexical decision

\section{RESUMO}

\section{Revisão sistemática de estudos de neuroimagem do priming semântico}

The present systematic review aims to address the contribution of brain imaging studies to the investigation of semantic priming (SP). Only studies from 2001 to 2017 using lexical decision tasks with visual and auditory stimuli, were considered. The review resulted in 20 articles, which showed semantic priming effects (SPE) in several brain areas (frontal and temporal lobes, cingulate gyrus, supplementary motor areas, and parietal cortex). In this way, the identification of activation in these areas varied as a function of stimulus onset asynchrony (SOA). Data suggests both hemispheres are involved on SPE, with a more robust role of the left hemisphere. Specifically, a decreased activation on the left middle temporal gyrus was found to be related to automatic SPE. This same area seemed to be related to SPE at long SOAs, along with the left inferior frontal gyrus and the anterior cingulated cortex. Therefore, a strong performance of the left hemisphere in semantic priming tasks could be observed, especially in the left middle temporal gyrus. Its activation was modulated by short and long intervals between stimuli, with more activation associated with longer intervals.

Palavras-chaves: fMRI; priming semântico; decisão lexical

Lexical decision is a process that is part of our day-to-day lives. When we read a word for the first time, for example, a series of cognitive processes take place from decoding the word to understand it in context and storing it in our mental lexicon. The more we encounter and read a word, the more automatic the word recognition process becomes. One of the questions addressed by cognitive psychology over the past decades is whether a semantically-related word can prime the identification of a subsequent word in lexical decision. For example, does

\section{Sobre os Autores}

C. S. Holderbaum orcid.org/0000-0002-9091-0651 Universidade Federal do Rio Grande do Sul (UFRGS) - Porto Alegre - RS

candicebaum@gmail.com

J. B. S.

orcid.org/ 0000-0001-9600-3318

Universidade Federal do Rio Grande do Sul (UFRGS) - Porto

Alegre - RS julianasbicigo@gmail.com

A. B.

orcid.org/ 0000-0003-3791

7472

Universidade Federal do Rio Grande do Sul (UFRGS) - Porto Alegre - RS

augusto.buchweitz@pucrs.br

J. F. S.

orcid.org/ 0000-0003-0877-488X Universidade Federal do Rio Grande do Sul (UFRGS) - Porto Alegre - RS

jerusasf@yahoo.com

\section{Direitos Autorais}

Este é um artigo de acesso aberto e pode ser reproduzido livremente, distribuído, transmitido ou modificado, por qualquer pessoa desde que usado sem fins comerciais. $O$ trabalho é disponibilizado sob a licença Creative Commons CCBY-NC.

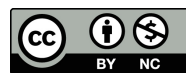


the word "table" prime the recognition of "chair" as a word faster than the semantically-unrelated "firetruck"? Thus, studies have clearly shown the semantic priming effect on the speed of lexical decision (e.g. Assink, Bergen, Teeseling, \& Knuijt, 2004; Simpson \& Foster, 1986). Semantic priming is usually defined as a facilitating effect on the processing of a stimulus due to the previous processing of a semantically related one (McNamara, 2005). This facilitation is observed experimentally in a reduction of reaction time (RT) or in an increase in accuracy in an experimental task.

The semantic priming effect (SPE) has been well investigated in studies of lexical decision. However, the neural mechanisms that underpin the processes of lexical decision involved in semantic priming are not fully understood. Regarding this issue, we will address lexical decision from the point of view of brain imaging studies and their contribution to understanding the cognitive processes that underpin the SPE in lexical decision. In this sense, the neural representation of semantic knowledge is distributed across the cortex; this has been shown, for example, in neuroimaging studies of brain damaged patients with semantic deficits (McClelland \& Rogers, 2003). Activation associated with the SPE, in turn, has been shown in brain lesion patients (Del Toro, 2000; Hagoort, 1997) and healthy participants (e.g., Liu, Hu, Peng, Yang, \& Li, 2010; Sass, Krach et al., 2009).

Semantic priming: automatic spreading activation and expectancy-based priming

The semantic priming paradigm is an established test for the influence of semantic relatedness on lexical decision. The SPE is the facilitation of the processing of a target word following the presentation of a semantically-related prime. In traditional semantic priming experiments, participants respond to a lexical decision task (decide whether the target is a real word or a pseudoword) or a naming task. In this task, the semantic contextualization effect is modulated by the relatedness between prime and target (related words; unrelated words; and neutral/nonlinguistic, for example, a series of hashtags). The relatedness between prime and target modulates the reaction time (RT) and accuracy in lexical decision tasks (Squire \& Kandel, 2003; Leritz, Grande, \& Bauer, 2006); the closer the semantic relation between prime and target, the faster and more accurately readers identify the target word as a word (fruit-apple versus an unrelated primetarget combination, such as fruit - hammer).

In addition to semantic relatedness, the variation in timing between the presentation of prime and target also modulates the priming effect by stimulus onset asynchrony (SOA) or interstimulus interval (ISI) (Holderbaum \& Salles, 2010, 2011). There are different theories that attempt to explain the semantic priming phenomenon, with the two main being (1) the automatic spreading activation theory (Collins \& Loftus, 1975) and (2) the expectancy-based priming theory (Becker, 1980). The main difference between the two theories is that they attempt to explain semantic priming effects in two different situations: shorter and longer stimuli onset asynchronies.

The automatic spreading activation theory is based on a general idea that reading (or listening) to a word activates its meaning and that activation, in turn, has an effect on words that are semantically related. Consequently, analogous to a situation in which shorter geographical distance favors the transposition of water from one river to another, the access to the meaning of the related words is faster while the prime is still active; more specifically, semantically/associatively related nodes have strong links and are "stored close together." When the prime is processed, activation spreads to the nodes of semantically-related targets; the spread of activation, successively, decreases the time required to activate the targets. According to Neely (1991), the process of spreading activation is automatic, that is, the reader has no volitional control over it. The automaticity of the process of spreading activation is the central explanation for the semantic priming effect in experiments with short SOAs.

Nonetheless, the definition of what constitutes a short SOA varies. Some authors define short SOAs as those shorter than $150 \mathrm{~ms}$ (Altarriba \& Basnight-Brown, 2007) or 300ms (Neely, 1991). However, most authors agree that intervals longer than 500ms will no longer be associated with automatic effects of priming. The classical criteria for establishing that a behavior is automatic are that the stimuli associated with the behavior almost always elicit the behavior (i.e., there is no volitional control), and that the process can be successfully executed while a secondary task is being performed (Schneider \& Shiffrin, 1977). More contemporarily, most authors understand that a skill or behavior becomes automatic with the transition from goal-directed behavior (controlled by executive processes) to one in which the strategic control drops away (Chein \& Schneider, 2005).

The expectancy-based priming theory (Becker, 1980) provides an account of SPE in longer SOAs [greater than $150 \mathrm{~ms}$ according to Altarriba and Basnight-Brown (2007) and greater than $300 \mathrm{~ms}$, according to Neely (1991)]. This theory postulates that, when the prime is processed, there is activation of a set of related targets. Subsequently, if the presented target is among the words related to the prime and, thus, activated above a certain threshold (i.e., when semantically-related and activated words separate from unrelated, non-activated words), the recognition of the target is facilitated, being, then, faster and more accurate (Nievas \& 
Justicia, 2004). This process is related to semantic relations that can be identified by the reader; so, the reader can establish the connections between words and ultimately be able to verbalize them. The process of facilitation and the relation between the prime and the target thus differ from automatic processes in semantic priming with short SOAs; in this case, the longer SOA allows for controlled, volitional processes to take place, such as the reader remembering a semantically-related word, episode, and so on.

Several studies have investigated semantic priming behaviorally with adults (e.g., Basnight-Brown \& Altarriba, 2007; Davenport \& Potter, 2005; Hutchison, 2007; Nobre \& McCarthy, 1995; Sánchez-Casas, Ferré, García-Albea, \& Guasch, 2006; Valdés, Catena, \& Marí-Beffa, 2005). Most of them have found SPE on SOAs varying from $50 \mathrm{~ms}$ to $1000 \mathrm{~ms}$, which includes both automatic and controlled processes.

More recently, brain imaging techniques have been used to investigate semantic priming tasks. These studies included the use of positron emission tomography - PET (e.g., Mummery, Shallice, \& Price, 1999) and functional magnetic resonance imaging - fMRI (e.g., Copland et al., 2003; Liu et al. 2010; Sass, Krach et al., 2009).

To our knowledge, there is no recent review of neuroimaging studies of semantic priming. In the past decade, Henson (2003) reviewed functional neuroimaging studies of priming, including word-stem completion, masked priming, repetition priming of visual objects, and semantic priming paradigms. In order to describe recent results, the present study aimed to review semantic priming studies published from 2001 to 2017, revising items such as sample characteristics, lexical decision task characteristics, fMRI procedures, and findings (areas of activation and processes of activation or deactivation)

\section{METHOD}

This article reviews functional magnetic resonance imaging studies of semantic priming published until September 2017. We searched for articles in the databases ISI Web of Knowledge, PubMed and Psychlnfo. The combination of the terms "semantic priming" and "fMRI" was used in the search (title and/or abstract). After removing repeated articles along the databases, we found sixteen eligible articles in the Web of Science database, four articles in Psycholnfo and no other articles in Pubmed.

On the one hand, we reviewed a total of 20 studies. On the other hand, we excluded review articles, abstracts from academic events, clinical samples, studies that used nonlexical decision tasks or that could have confounding variables (for example dopaminergic neuromodulation). The information we reviewed in the 20 papers selected included sample, design, stimuli, trial (SOA, ITI- inter-trial interval, prime and target duration), $\mathrm{fMRI}$ procedures and the results themselves. TheGingerALE 2.3 software (Eickhoff et al., 2009; Eickhoff, Bzdok, Laird, Kurth, \& Fox, 2012; Turkeltaub et al., 2012) was used to generate the agglutination of the brain activations related to semantic priming in the reviewed studies. The centroids are presented in Talairach coordinates; studies that reported $\mathrm{MNI}$ coordinates were converted to Talairach.

\section{RESULTS AND DISCUSSION}

This section presents the description of the studies' participants, lexical decision tasks and fMRI procedures and findings. Table 1 shows the 20 reviewed articles, including sample size, mean age of participants, study design (block design or event-related) and modality of the stimuli used (visual, auditory or both).

\section{POPULATION CHARACTERISTICS}

Studies evaluated young adults whose ages ranged from 20.8 to 31.8 years (mean 25.5, SD 1.4). An exception was Gold et al. (2009) which included an elderly group of participants (mean 74.7 years); All the studies analyzed did not report participants' schooling.

The number of participants ranged from eight to thirty; Gold et al. (2006) were the only ones to investigate a larger population sample (24 participants in three experiments). Approximately two-thirds of the studies used visual stimuli. The remaining studies used auditory or a combination of visual and auditory stimuli. Stimulus modality has been associated with differences in activation; in experiments that postulate SPE, brain activation decreases for longer SOAs in visual experiments, but increases for longer SOAs in auditory experiments (Anderson \& Holcomb, 1995).

\section{DESIGN}

The review shows the variability in experimental conditions; for example, some of the study designs included three conditions - related word pairs, unrelated word pairs and pseudoword target pairs (e.g.: Kircher et al., 2009; Rissman et al., 2003, Ruff et al., 2008). Other studies divided the related prime-target combinations into strong and weak association strengths (Tivarus et al., 2006; Wible et al., 2006) or into thematic and categorical association (Kotz et al., 2002; Sachs et al., 2008; Sachs et al., 2011, Sass et al., 2009). Approximately half the studies included fixation trials as the baseline (e.g. Gold et al., 2009; Matsumoto et al., 2005; 


\section{N"INTERACÃO EM PSICOLOGIA}

Table 1. Sample size, Age of Participants, Study Design and Stimuli Modality of Reviewed Studies

\begin{tabular}{lcccc}
\hline \multicolumn{1}{c}{ Author/Year } & N & Mean age & Design & Modality \\
\hline Rossell, Bullmore, Williams, and David (2001) & 12 & 31.8 & block & Visual \\
Kotz, Cappa, von Cramon, and Friederici (2002) & 13 & 23.5 & ER & Auditory \\
Rossell, Price, and Nobre (2003) & 8 & 23 & ER & Visual \\
Copland et al. (2003) & 12 & 25 & ER & Visual \\
Rissman, Eliassen, and Blumstein (2003) & 15 & 22.9 & ER & Auditory \\
Matsumoto, Lidaka, Haneda, Okada, and Sadato (2005) & 12 & 20.8 & ER & Visual \\
Gold et al. (2006) & 72 & 23.4 & ER & Visual \\
Tivarus, Ibinson, Hillier, Schmalbrock, and Beversdorf & 12 & 25.8 & block & Visual \\
(2006) & 13 & 24 & ER & Auditory \\
Wible et al. (2006) & 14 & 26 & ER & Visual \\
Copland, de Zubicaray, McMahon, and Eastburn (2007) & 17 & NM & ER & Visual \\
O'Hare, Diena, Watersona, and Savageb (2008) & 16 & 27 & ER & Visual \\
Sachs et al. (2008) & 15 & 21.4 & ER & Auditory \\
Ruff, Blumstein, Myers, and Hutchison (2008) & 15 & 26.8 & ER & Both \\
Sass, Krach, Sachs, and Kircher (2009) & 16 & 26 & ER & Auditory \\
Sass, Sachs, Krach, and Kircher(2009) & $15 / 14$ & $22.9 / 74.7$ & ER & Visual \\
Gold, Andersen, Jicha, and Smith (2009) & 16 & 26 & ER & Both \\
Kircher, Sass, Sachs, and Krach (2009) & 15 & NM & ER & Visual \\
Liu et al. (2010) & 16 & 27 & ER & Visual \\
Sachs et al. (2011) & 30 & 21 & ER & Visual \\
Lau, Weber, Gramfort, Hämäläinen, and Kuperberg (2014) & & & &
\end{tabular}

Note: $\mathrm{NM}$ = not mentioned; $\mathrm{ER}$ = event-related.

Rossell et al., 2003); the other half did not include a resting baseline to compare brain activation between conditions (related versus unrelated; unrelated $\mathrm{x}$ related; Kotz et al., 2002; Sachs et al., 2008; Sachs et al., 2011, Sass et al., 2009).

\section{STIMULI}

The selection of semantically-related pairs was based on previously published norms of semantic association or ambiguity (e.g., Copland et al., 2003; O`Hare et al., 2008; Rossell et al., 2001; Ruff et al., 2008). Some studies, however, normed their stimuli by asking participants to rate the semantic relation between prime and target words (Liu et al., 2010; Kircher et al., 2009; Sachs et al., 2008; Sass et al., 2009). Yet some experiments used previously-designed stimuli (e.g., Gold et al., 2006; Rissman et al., 2003). The number of trials ranged from 80 to 720 . The most frequent number of trials used was 150 (Copland et al., 2003; Copland et al., 2007; Matsumoto et al., 2005). All studies with the exception of Kircher et al. (2009) were concluded in one session; studies with a larger number of trials were divided in up to four blocks of stimuli (Gold et al., 2009; Kotz et al., 2002;
Liu et al., 2010).

\section{DURATION OF TRIALS AND INTERTRIAL/INTERSTIMULUS INTERVALS}

One of the major contentions in the literature is whether the SPE is determined by automatic or strategic (controlled) mechanisms. Even though the two mechanisms do not operate in total isolation (McNamara, 2005), the design of the task may favor one or another. SOA determines whether processes activated during semantic priming are automatic or controlled. We use the definitions according to Neely (1991) for short and long SOA. In the articles revised, the SOA varied from $50 \mathrm{~ms}$ to $1000 \mathrm{~ms}$; thus, the studies analyzed included priming tasks in which SPE involves automatic (range from 50 to 300; Copland et al., 2003; Liu et al., 2010; Sachs et al., 2008) and controlled processes (range from 350 to 1000; Copland et al., 2007; Sachs et al., 2011; Wible et al., 2006). SOA was manipulated as an independent variable in three studies (Rossell et al., 2001; Rossell et al., 2003; Gold et al., 2006) that used both short and long SOAs to verify differences in SPE associated with automatic or controlled processes. Table 2 shows the design of the studies. 


\section{W'INTERACÃO EM PSICOLOGIA}

Table 2. Design of Revised Semantic Priming Studies

\begin{tabular}{lccccc}
\hline \multicolumn{1}{c}{ Author/Year } & SOA $(\mathrm{ms})$ & Prime $(\mathrm{ms})$ & Target $(\mathrm{ms})$ & ITI & Cue \\
\hline Rossell et al. (2001) & $200 / 1000$ & 200 & 2000 & $\mathrm{NR}$ & no \\
Kotz et al. (2002) & $\mathrm{NR}$ & $\mathrm{NR}$ & $\mathrm{NR}$ & 8000 & no \\
Rossell et al. (2003) & $200 / 1000$ & 150 & 150 & $\mathrm{NR}$ & $50-1150$ \\
Copland et al. (2003) & 150 & 150 & 2000 -response & $2000-18000$ & 500 \\
Rissman et al. (2003) & 600 & 540 & 530 & $\mathrm{NM}$ & no \\
Matsumoto et al. (2005) & 600 & 400 & 1000 & 3000 & 400 \\
Gold et al. (2006) & $150-1000$ & $150-1000$ & 1300 & $200-950$ & NR \\
Tivarus et al. (2006) & 700 & 400 & 1300 & 1000 & NR \\
Wible et al. (2006) & 750 & $\mathrm{NR}$ & $\mathrm{NR}$ & $\mathrm{NR}$ & no \\
Copland et al. (2007) & 1000 & 500 & $2000-$ response & $2000-18000$ & 500 \\
O'Hare et al. (2008) & 500 & 150 & 150 & 3500 & no \\
Sachs et al. (2008) & 200 & 200 & 1000 & $2500-8000$ & 800 \\
Ruff et al. (2008) & $\mathrm{NR}$ & $\mathrm{NR}$ & $\mathrm{NR}$ & $\mathrm{NR}$ & no \\
Sass, Krach et al. (2009) & 350 & 350 & 1000 & $1500-5000$ & 500 \\
Sass, Sachs et al. (2009) & 350 & 350 & 1000 & $1500-5000$ & no \\
Gold et al. (2009) & 250 & 250 & 1350 & 400 & no \\
Kircher et al. (2009) & 350 & 350 & 1000 & $1500-5000$ & 500 \\
Liu et al. (2010) & 50 & 50 & 1150 & 350 & 150 \\
Sachs et al. (2011) & 800 & 800 & 1000 & $2500-8000$ & 800 \\
Lau et al. (2014) & NR & 500 & 900 & NR & no \\
\hline
\end{tabular}

Note. SOA=stimulus onset asynchrony; ITI = inter-trial interval; NR = not reported.

Nearly half the studies chose to present the target following the prime, without intervals (no interstimulus interval; ISI); in these studies, the SOA equaled the duration of the presentation of the prime. The presentation, or not, of a cue before the prime is another difference between studies; also, the duration of the cue ranged from 50 to $1150 \mathrm{~ms}$. The duration of presentation of the prime ranged from 50 to $1000 \mathrm{~ms}$, and of the target, from $150-2000 \mathrm{~ms}$; inter-trial interval (ITI) ranged from 200 to $18000 \mathrm{~ms}$. The use of different experiment designs may have a direct impact on the processing time of prime and target.

\section{PROCEDURES}

Most studies adopted event-related designs, with the exception of Rossell et al. (2001) and Tivarus et al. (2006), who used block designs. The event-related design offers some advantages when compared to block design. The use of events allows better decomposition of brain activation for specific events (Donaldson \& Buckner, 2001; Huettel, Song, \& McCarthy, 2009). Event-related experiments should consider ways to better investigate the time course for the hemodynamic responses. Alternatives to that include for example using a jittered ITI. The other studies reported using ITI, which generally were not multiples of the TR (i.e., jittered
ITI). Among the 17 event-related studies, five did not report the ITI (Gold et al., 2006; Kotz, et al., 2002; Liu et al., 2010; Matsumoto et al., 2005; Wible et al., 2006).

\section{AREAS OF BRAIN ACTIVATION ASSOCIATED WITH LONG AND SHORT SOA TASKS}

The results of the studies show a distributed neural network associated with automatic and controlled lexical decision processes (automatic vs. controlled priming). There were differences associated with the automaticity and control and with the modality of stimuli presentation. For studies that used ambiguous stimuli (i.e.; a dominant and subordinated condition based on word meanings) as an independent variable, we considered only the dominant versus unrelated conditions. Experiments that do not use ambiguous stimuli usually present pairs of words related to condition that have intermediate or strong semantic association strength. Finally, Kotz et al. (2002) and Ruff et al. (2008) did not report the SOA used in their tasks and therefore were excluded from the final analysis.

One of the common findings between studies was more activation of the left middle temporal gyrus (MTG) for the unrelated pairs in comparison to the related pairs of words. 
Activation of the left MTG is associated with semantic memory and semantic processing (Copland et al., 2003; Rossell et al., 2001); it is also associated with lexicalsemantic processes, such as semantic priming, lexical decision and semantic judgments (e.g. Friederici, Opitz, \& Cramon, 2000). The modulation of left MTG activation can be explained by the automatic spreading activation theory (Collins \& Loftus, 1975); the lexical choice facilitated by the semantic association between prime and target is associated with the reduction of activation for pairs of related words compared with pairs of unrelated words.

Less activation of areas associated with strategic control suggest more automatic lexical decision processes. As mentioned before, the contemporary view of automaticity postulates that a behavior becomes automatic when there is a transition from goal-directed behavior controlled by a frontal-parietal executive system to a state in which the frontal strategic control drops away (Just \& Buchweitz, 2014). Regarding this issue, tasks can be considered automatic in terms of the neural systems they engage, if they do not require appreciable executive control by the frontal-parietal systems. The strategic control mechanism entails processes executed in the middle frontal gyrus, anterior cingulate, left insula, bilateral parietal, and occipito-temporal areas (Chein \& Schneider, 2005). Though not robustly, the results from our review suggest activation of the anterior cingulate cortex only in one study of long SOA. Also, three studies with long SOA, and one with short SOA reported activation of the middle frontal gyrus (see Tables 3 and 4).

Studies that applied long SOAs show bilateral MTG activation. Tables 5 and 6 show the areas of brain activation related to SPE on experiments with SOAs longer than $300 \mathrm{~ms}$.
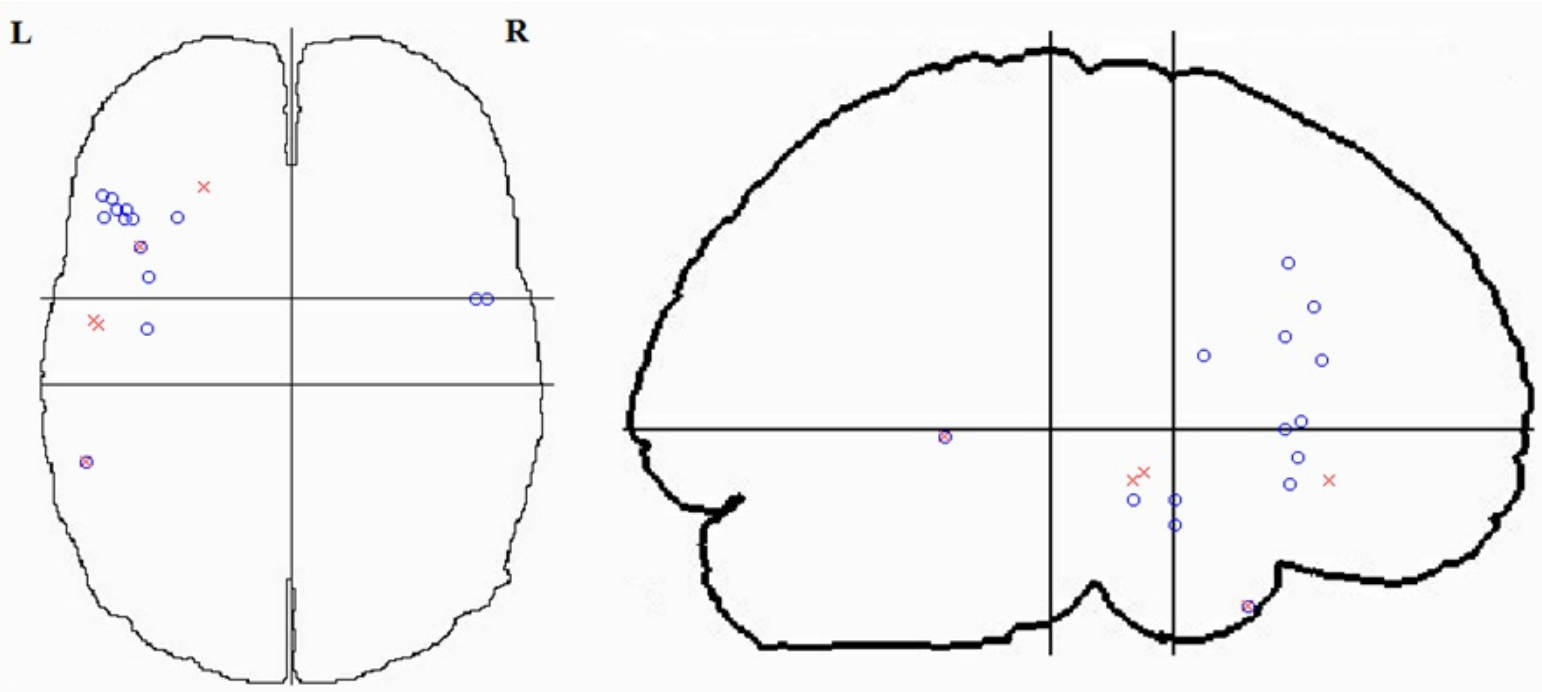

Figure 1. Agglutination of activations of brain areas in semantic priming effects in the reviewed studies. Centroids of activation with long SOA (blue circle) and short SOA (red X) in the LIFG and LMTG.

Table 3. Brain Areas Associated with Semantic Priming Effects (short SOA) - Left Hemisphere

\begin{tabular}{|c|c|c|c|c|c|c|c|c|c|c|c|}
\hline \multicolumn{12}{|c|}{ Left Hemisphere } \\
\hline & IPFC & IFG & MFG & MTG & ITG & PO & SMG & IOG & MOG & MCG & MFUG \\
\hline Rossell et al. (2001) & & & & $x$ & & & & & & & \\
\hline Rossell et al. (2003) & & & & $x$ & & & $y$ & & & & \\
\hline Copland et al. (2003) & $\mathrm{x}$ & & & $x$ & & & & & & & \\
\hline Gold et al. (2006) & & & & $x$ & & & & & & & $x$ \\
\hline \multicolumn{12}{|l|}{ Sachs et al. (2008) } \\
\hline Gold et al. (2009) & & & & & & & & & & & $x$ \\
\hline Liu et al. (2010) & & $x$ & $x$ & $x$ & $x$ & $x$ & & $\mathrm{y}$ & y & $x$ & \\
\hline
\end{tabular}




\section{W' INTERACÃO EM ET PSICOLOGIA}

Table 4. Brain Areas Associated with Semantic Priming Effects (short SOA) - Right Hemisphere

\begin{tabular}{|c|c|c|c|c|c|c|c|c|}
\hline \multicolumn{9}{|c|}{ Right Hemisphere } \\
\hline & STG & MFG & SFG & IN & PCG & PCU & PCEG & ACG \\
\hline Rossell et al. (2001) & $x$ & & & $x$ & $x$ & & & \\
\hline \multicolumn{9}{|l|}{ Rossell et al. (2003) } \\
\hline \multicolumn{9}{|l|}{ Copland et al. (2003) } \\
\hline \multicolumn{9}{|l|}{ Gold et al. (2006) } \\
\hline Sachs et al. (2008) & & $x$ & & & & $x$ & $x$ & $x$ \\
\hline \multicolumn{9}{|l|}{ Gold et al. (2009) } \\
\hline Liu et al. (2010) & $x$ & $x$ & & & & & & \\
\hline
\end{tabular}

\footnotetext{
Note. STG = superior temporal gyrus; MFG = middle frontal gyrus; SFG = superior frontal gyrus; $I N$ = insula; $P C G$ = posterior cingulate gyrus; $P C U=$ precuneus; $P C E G=$ postcentral gyrus; $A C G=$ anterior cingulate gyrus. $x=$ results from unrelated > related conditions; $y=$ results from related $>$ unrelated conditions
}

That was a common result for the studies applying long and short SOAs. Activation was reported for the frontal and temporal lobe, including the inferior frontal gyrus (IFG), middle frontal gyrus (MFG), middle temporal gyrus (MTG), and superior temporal gyrus (STG). Left IFG activation is associated with the controlled characteristic of the SPE; it may be associated with the executive control of retrieval and selection from semantic memory (e.g. Rossell et al., 2003; Sachs et al., 2011). The left IFG was not consistently reported to be activated in studies with short SOAs. Already the finding that LIFG activates with long SOA, but not with short SOA, suggests more strategic control processes in long SOA tasks. Figure 1 shows the centroids of activation for studies with long and short SOA tasks that reported LIFG activation (LMTG also shown). The blue circles in the glass-brain figure show the centroids for long SOA tasks; the red crosses showthose for the short SOA tasks. There is clearly more activation in frontal lobe areas for the studies with long SOA. Activation of left MTG was found in both short and long SOAs; this suggests a role of this area for lexical-semantic processes in

Table 5. Brain Areas Associated With Semantic Priming Effects (Long SOA) - Left Hemisphere

\begin{tabular}{|c|c|c|c|c|c|c|c|c|c|c|c|c|c|}
\hline \multicolumn{14}{|c|}{ Left Hemisphere } \\
\hline & $\mathrm{IFG}$ & MFG & MTG & STG & STS & ITG & SMG & PCS & $\mathrm{ACC}$ & PCEG & MFFG & $\mathrm{PCU}$ & $\mathrm{PU}$ \\
\hline $\begin{array}{l}\text { Rossell et al. } \\
(2001)\end{array}$ & & & $x$ & & & & & & & & & & $x$ \\
\hline $\begin{array}{l}\text { Rossell et al. } \\
(2003)\end{array}$ & & & $\mathrm{x}$ & & & & $y$ & & y & & & & \\
\hline $\begin{array}{l}\text { Rissman et al. } \\
\text { (2003) }\end{array}$ & & $x$ & & & & & & & & $x$ & & & \\
\hline $\begin{array}{l}\text { Matsumoto et al. } \\
(2005)\end{array}$ & $x$ & & & & & & & & & & & & \\
\hline $\begin{array}{l}\text { Tivarus et al. } \\
(2006)\end{array}$ & $x$ & $x$ & & & & & & & & & & & \\
\hline $\begin{array}{l}\text { Wible et al. } \\
(2006)\end{array}$ & $x$ & & & $x$ & & $x$ & & & & & & y & \\
\hline Gold et al. (2006) & & & $x$ & & & & & & & & $x$ & & \\
\hline $\begin{array}{l}\text { Copland et al. } \\
\text { (2007) }\end{array}$ & y & & & & & & & & & & & & \\
\hline $\begin{array}{l}\text { O'Hare et al. } \\
(2008)\end{array}$ & $\mathrm{x}$ & & & & & & & $y$ & & & & & \\
\hline $\begin{array}{l}\text { Kircher et al. } \\
(2009)\end{array}$ & $x$ & & & & & & & & & & & & \\
\hline $\begin{array}{l}\text { Sass, Krach et al. } \\
2009\end{array}$ & $y$ & $\mathrm{y}$ & & $\mathrm{y}$ & & & & & & & & y & \\
\hline $\begin{array}{l}\text { Sass, Sachs et al. } \\
2009\end{array}$ & & & & & $\mathrm{y}$ & & & & & & & & \\
\hline $\begin{array}{l}\text { Sachs et al. } \\
\text { (2011) }\end{array}$ & & & & & & & & & & & & & \\
\hline
\end{tabular}




\section{W'INTERACÃO EM ET PSICOLOGIA}

Table 6. Brain Areas Associated with Semantic Priming Effects - SPE (Long SOA) - Right Hemisphere

\begin{tabular}{|c|c|c|c|c|c|c|c|c|c|c|c|c|c|}
\hline \multicolumn{14}{|c|}{ Right Hemisphere } \\
\hline & STG & $\mathrm{HI}$ & MFG & SFG & IN & PCG & MCG & $\mathrm{PCU}$ & PCEG & PU & $\mathrm{CAU}$ & PCS & $\mathrm{ACC}$ \\
\hline $\begin{array}{l}\text { Rossell et al. } \\
(2001)\end{array}$ & $x$ & & & & $x$ & $x$ & & & & & & & \\
\hline $\begin{array}{l}\text { Rossell et al. } \\
(2003)\end{array}$ & & & & & & & & & & & & & \\
\hline $\begin{array}{l}\text { Rissman et } \\
\text { al. (2003) }\end{array}$ & & & $x$ & & & & & & & & $x$ & & \\
\hline $\begin{array}{l}\text { Matsumoto } \\
\text { et al. (2005) }\end{array}$ & & & & & & & & & & & & & $\mathrm{x}$ \\
\hline $\begin{array}{l}\text { Tivarus et al. } \\
(2006)\end{array}$ & & & $x$ & & & & & & & & & & \\
\hline $\begin{array}{l}\text { Wible et al. } \\
(2006)\end{array}$ & & & & & & & & & & & & & $x$ \\
\hline $\begin{array}{l}\text { Gold et al. } \\
(2006)\end{array}$ & & & & & & & & & & & & & \\
\hline $\begin{array}{l}\text { Copland et al. } \\
(2007)\end{array}$ & $x$ & & & & & & & & & & & & $y$ \\
\hline $\begin{array}{l}\text { O`Hare et al. } \\
(2008)\end{array}$ & & & & & & $y$ & & & & & & $\mathrm{y}$ & \\
\hline $\begin{array}{l}\text { Kircher et al. } \\
(2009)\end{array}$ & $x$ & & $x$ & & & & & $x$ & $x$ & & & & \\
\hline $\begin{array}{l}\text { Sass, Krach } \\
\text { et al. } 2009\end{array}$ & & & & & & & & & & $x$ & & & \\
\hline $\begin{array}{l}\text { Sass, Sachs } \\
\text { et al. } 2009\end{array}$ & & $\mathrm{y}$ & & & & & $\mathrm{y}$ & & & & & & \\
\hline $\begin{array}{l}\text { Sachs et al. } \\
(2011)\end{array}$ & & & & $x$ & & & & & & & & & \\
\hline
\end{tabular}

general (Rossell et al., 2003; Copland et al., 2003; Liu et al., 2010).

Activation of areas of the right hemisphere in lexical decision tasks included the superior temporal gyrus (STG), middle frontal gyrus (MFG) and the anterior cingulate cortex (ACC). The activation of the right MFG may be associated with the strategic, controlled process involved in SPE with long SOAs. This area was associated with extensive mental search in the semantic network, higher retrieval effort, and decision uncertainty (Kotz et al., 2002; Sachs et al., 2008; Sass, Krach et al., 2009; Tivarus et al., 2006). Moreover, ACC activation may result from the online monitoring performance function of this area (Carter et al., 1998).

Comparisons between Table 3, 4 and 5 show more brain areas activated overall for studies that used long SOA. SPE at short SOA is associated with less activation overall, whereas SPE at long SOAs was associated with more activation overall. This finding corroborates earlier predictions that controlled SPE should trigger more cerebral activity for the related versus unrelated conditions (Mummery et al., 1999).

\section{FINAL CONSIDERATIONS}

The aim of the present study was to review semantic priming studies using lexical decision tasks published from 2001 to 2017. The analysis of 20 articles showed different patterns of brain activation when comparing studies with short and long SOAs. Experiments using SOAs shorter than $300 \mathrm{~ms}$ found most frequently less activation for the left middle temporal gyrus (MTG) in the related word pair conditions relative to the unrelated word pair conditions (Copland et al., 2003; Gold et al., 2006; Liu et al., 2010; Rossell et al., 2001; Rossell et al., 2003). Experiments that used SOAs longer than $300 \mathrm{~ms}$ found more common areas of activation, including the left inferior frontal gyrus (IFG) (e.g. Matsumoto et al., 2005; Tivarus et al., 2006; Wible et al., 2006), and anterior cingulate cortex (ACC) (Copland et al., 2007; Matsumoto et al., 2005; Wible et al., 2006). SPE has been associated with inferior and superior temporal lobe (Verfaellie \& Keane, 1997), left pre-frontal cortex (Raichle, Fiez, \& Videen, 1994; Demb, Desmond, \& Wagner, 1995), left inferior frontal and left medial and inferior temporal gyri activation (Blaxton, 
1999). There is converging evidence in relation to the specific involvement of areas of the brain associated with controlled, strategic processes for semantic priming tasks with long SOA, and for less activation overall associated with semantic priming tasks with short SOA. There is also converging evidence for the expected involvement of temporal-lobe structures; however, the variability in experimental design and choice of stimuli and analyses also reflects in a diverse network of areas found in different experiments.

The studies show a clear role of left hemisphere for automatic and controlled SPE. One question that may arise at this point is to understand brain plasticity processes in adult patients with left-hemisphere brain lesions who are able to perform lexical decision tasks. Different areas of the left hemisphere are activated or deactivated depending on short or long SOA experiments; a question that arises is whether patients with left-hemisphere temporal-lobe lesions perform equally well on short and long SOA experiments. At last, the present study did not review all studies that investigated SPE neural basis through fMRI exams; the findings discussed here apply exclusively to the studies that met the review criteria.

\section{DECLARAÇÃO DE FINANCIAMENTO}

Os autores declaram que a pesquisa aqui relatada foi feita com financiamento próprio.

\section{CONTRIBUIÇÃO DE CADA AUTOR}

C.S.H. foi responsável pela fundamentação teórica do artigo (introdução e discussão) e contribuiu realizando a busca por revisão sistemática, avaliando os artigos pertinentes ao objetivo do estudo; J.B.S. contribuiu realizando a busca por revisão sistemática, avaliando os artigos pertinentes ao objetivo do estudo e revisão da redação; A. B. e J. F.S contribuíram em todas as seções do artigo, realizando a revisão final no manuscrito.

\section{DECLARAÇÃO DE CONFLITOS DE INTERESSE}

Os autores declaram que não existem conflitos de interesse no artigo submetido.

\section{REFERENCES}

Altarriba, J., \& Basnight-Brown, D. M. (2007). Methodological considerations in performing semantic - and translation - priming experiments across languages. Behavior Research Methods, 39(1), 1-18. doi: 10.3758/BF03192839
Anderson, J. E., \& Holcomb, P. J. (1995). Auditory and visual semantic priming using different stimulus onset asynchronies: an event-related brain potential study. Psychophysiology, 32(2), 177-190.

Assink, E. M., Bergen, F. V., Teeseling, H. V., \& Knuijt, P. P. (2004). Semantic priming effects in normal versus poor readers. The Journal of Genetic Psychology, 165(1), 6779.

Basnight-Brown, D. M., \& Altarriba, J. (2007). Differences in semantic and translation priming across languages: the role of language direction and language dominance. Memory and Cognition, 35(5), 953-965.

Becker, A. C. (1980). Semantic contexts effects in visual word recognition: an analysis of semantic strategies. Memory and Cognition, 8(6), 493-512.

Blaxton, T. (1999). Cognition: memory, 2: conceptual and perceptual memory. American Journal of Psychiatry, 156(11), 1676.

Carter, C. S., Braver, T. S., Barch, D. M., Botvinick, M. M., Noll, D., \& Cohen, J. D. (1998). Anterior cingulate cortex, error detection, and the online monitoring of performance. Science, 280, 747-749.

Chein, J. M., \& Schneider, W. (2005). Neuroimaging studies of practice-related change: $\mathrm{fMRI}$ and meta-analytic evidence of a domain-general control network for learning. Brain Research. Cognitive Brain Research, 25(3), 607-623. doi: 10.1016/j.cogbrainres.2005.08.013

Collins, A. M., \& Loftus, E. F. (1975). A spreading-activation theory of semantic processing. Psychological Review, 82(6), 407-428.

Copland, D. A., de Zubicaray, G. I., McMahon, K., \& Eastburn, M. (2007). Neural correlates of semantic priming for ambiguous words: an event-related fMRI study. Brain Research, 1131(1), 163-172.

Copland, D. A., de Zubicaray, G. I., McMahon, K., Wilson, S. J., Eastburn, M., \& Chenery, H. J. (2003). Brain activity during automatic semantic priming revealed by event-related functional magnetic resonance imaging. Neuroimage, 20(1), 302-310.

Davenport, J. L., \& Potter, M. C. (2005). The locus of semantic priming in RSVP target search. Memory and Cognition, 33(2), 241-248.

Del Toro, J. F. (2000). An examination of automatic versus strategic semantic priming effects in Broca's aphasia. Aphasiology, 14(9), 925-947.

Demb, J., Desmond, J., \& Wagner, A. (1995). Semantic encoding and retrieval in the left inferior prefrontal cortex: a functional MRI study of task difficulty and process specificity. Journal of Neuroscience, 15(9), 5870-5878. 
Donaldson, D. I., \& Buckner, R. L. (2001). Effective paradigm design. In P. M. Matthews, P. Jezzard, \& A. C. Evans (Eds.), Functional Magnetic Resonance Imaging of the Brain: Methods for Neuroscience. Oxford: Oxford University Press.

Eickhoff, S. B., Bzdok, D., Laird, A. R., Kurth, F., \& Fox, P. T. (2012). Activation likelihood estimation meta-analysis revisited. Neurolmage, 59(3), 2349-61. doi: 10.1016/ j.neuroimage.2011.09.017

Eickhoff, S. B., Laird, A. R., Grefkes, C., Wang, L. E., Zilles, K., \& Fox, P. T. (2009). Coordinate-based activation likelihood estimation meta-analysis of neuroimaging data: a randomeffects approach based on empirical estimates of spatial uncertainty. Human Brain Mapping, 30(9), 2907-26. doi: 10.1002/hbm.20718

Friederici, A. D., Opitz, B., \& Cramon, D. Y. (2000). Segregating semantic and syntactic aspects of processing in the human brain: an fMRI investigation of different word types. Cerebral Cortex, 10(7), 698-705.

Gold, B. T., Andersen, A. H., Jicha, G. A., \& Smith, C. D. (2009). Aging influences the neural correlates of lexical decision but not automatic semantic priming. Cerebral Cortex, 19(11), 2671-2679.

Gold, B. T., Balota, D. A., Jones, S. J., Powell, D. K., Smith, C. D., \& Andersen, A. H. (2006). Dissociation of automatic and strategic lexical-semantics: functional magnetic resonance imaging evidence for differing roles of multiple frontotemporal regions. Journal of Neuroscience, 26(24), 6523-6532.

Hagoort, P. (1997). Semantic priming in Broca's aphasics at a short SOA: no support for an automatic access deficit. Brain and Language, 56(2), 287-300.

Henson, R. N. A. (2003). Neuroimaging studies of priming. Progress in Neurobiology, 70(1), 53-81.

Holderbaum, C. S., \& Salles, J. F. (2010). Efeitos de priming semântico em crianças conforme a característica dos estímulos (força de associação e frequência na língua). Aletheia (ULBRA), 33, 95-108.

Holderbaum, C. S., \& Salles, J. F. (2011). Semantic priming effect in a lexical decision task: comparing third graders and college students in two different stimulus onset asynchrony. The Spanish Journal of Psychology, 14(2), 589-599.

Hutchison, K. A. (2007). Attentional control and the relatedness proportion effect in semantic priming. Journal of Experimental Psychology: Learning, Memory and Cognition, 33(4), 645-662.

Huettel, S. A., Song, A. W., \& McCarthy, G. (2009). Functional Magnetic Resonance Imaging (2 ed.). Massachusetts: Sinauer.
Just, M. A., \& Buchweitz, A. (2014). What brain imaging reveals about the nature of multitasking. In S. Chipman (Ed.), The Oxford Handbook of Cognitive Science (pp. 116). New York: The Oxford University Press. doi: 10.1093/ oxfordhb/9780199842193.013.4

Kircher, T., Sass, K., Sachs, O., \& Krach, S. (2009). Priming words with pictures: neural correlates of semantic associations in a cross-modal priming task using fMRI. Human Brain Mapping, 30(12), 4116-4128.

Kotz, S. A., Cappa, S. F., von Cramon, D. Y., \& Friederici, A. D. (2002). Modulation of the lexical semantic network by auditory semantic priming: an event-related functional MRI study. Neuroimage, 17(4), 1761-1772.

Lau, E. F., Weber, K., Gramfort, A., Hämäläinen, M. S., \& Kuperberg, G. R. (2014). Spatiotemporal signatures of lexical-semantic prediction. Cerebral Cortex, 26(4), 13771387.

Leritz, E. C., Grande, L. J., \& Bauer, R. M. (2006). Temporal lobe epilepsy as a model to understand human memory: the distinction between explicit and implicit memory. Epilepsy \& Behavior, 9(1), 1-13.

Liu, H., Hu, Z., Peng, D., Yang, Y., \& Li, K. (2010). Common and segregated neural substrates for automatic conceptual and affective priming as revealed by event-related functional magnetic resonance imaging. Brain \& Language, 112(2), 121-128.

Matsumoto, A., Lidaka, T., Haneda, K., Okada, T., \& Sadato, N. (2005). Linking semantic priming effect in functional MRI and event-related potentials. Neuroimage, 24(3), 624634.

McClelland, J. L., \& Rogers, T. T. (2003). The parallel distributed processing approach to semantic cognition. Nature Reviews Neuroscience, 4, 310-322.

McNamara, T. P. (2005). Semantic priming: perspectives from memory and word recognition. New York: Routledge.

Mummery, C. J., Shallice, T., \& Price, C. J. (1999). Dualprocess model in semantic priming: a functional imaging perspective. Neuroimage, 9(5), 516-525.

Neely, J. H. (1991). Semantic priming effects in visual word recognition: a selective review of current findings and theories. In D. Besner, \& G.W. Humphreys (Orgs.), Basic Processes in reading, visual word recognition (pp.264336). New Jersey: Lawrence Erlbaum Associates.

Nievas, F., \& Justicia, F. (2004). A cross-sectional study about meaning access processes for homographs. Cognitive Development, 19(1), 95-109.

Nobre, A. C., \& McCarthy, G. (1995). Language-related field potentials in the anterior-medial temporal lobe: II. Effects of word type and semantic priming. The Journal of Neuroscience, 15(2), 1090-1098. 
O'Hare, A. J., Diena, J., Watersona, L. D., \& Savageb, C. R. (2008). Activation of the posterior cingulate by semantic priming: a co-registered ERP/fMRI study. Brain Research, 1189, 97-114.

Raichle, M., Fiez, J. A., \& Videen, T. O. (1994). Practice-related changes in human brain functional anatomy during nonmotor learning. Cerebral Neocortex, 4(1), 8-26.

Rissman, J., Eliassen, J. C., \& Blumstein, S. E. (2003). An event-related FMRI investigation of implicit semantic priming. Journal of Cognitive Neuroscience, 15(8), 11601175.

Rossell, S. L., Price, C. J., \& Nobre, A. C. (2003). The anatomy and time course of semantic priming investigated by $\mathrm{FMRI}$ and ERPs. Neuropsychologia, 41(5), 550-564.

Rossell, S. L., Bullmore, E. T., Williams, S. C. R., \& David, A. S. (2001). Brain activation during automatic and controlled processing of semantic relations: a priming experiment using lexical-decision. Neuropsychologia, 39(11), 11671176.

Ruff, I., Blumstein, S. E., Myers, E. B., \& Hutchison, E. (2008). Recruitment of anterior and posterior structures in lexicalsemantic processing: an fMRI study comparing implicit and explicit tasks. Brain and Language, 105(1), 41-49.

Sachs, O., Weis, S., Zellagui, N., Huber, W., Zvyagintsev, M., Mathiak, K., \& Kircher, T. (2008). Automatic processing of semantic relations in fMRI: neural activation during semantic priming of taxonomic and thematic categories. Brain Research, 1218, 194-205.

Sachs, O., Weis, S., Zellagui, N., Sass, K., Huber, W., Zvyagintsev, M., ... Kircher, T. (2011). How different types of conceptual relations modulate brain activation during semantic priming. Journal of Cognitive Neuroscience, 23(5), 1263-73.

Sánchez-Casas, R., Ferré, P., García-Albea, J. E., \& Guasch, M. (2006). The nature of semantic priming: effects of the degree of semantic similarity between primes and targets in Spanish. The European Journal of Cognitive Psychology, 18(2), 161-184. doi: 10.1080/09541440500183830

Sass, K., Krach, S., Sachs, O., \& Kircher, T. (2009). Lion - tiger - stripes: neural correlates of indirect semantic priming across processing modalities. Neuroimage, 45(1), 224236.
Sass, K., Sachs, O., Krach, S., \& Kircher, T. (2009). Taxonomic and thematic categories: neural correlates of categorization in an auditory-to-visual priming task using fMRI. Brain Research, 1270, 78-87.

Schneider, W., \& Shiffrin, R. M. (1977). Controlled and automatic human information processing: 1. Detection, search, and attention. Psychological Review, 84(1), 1-66.

Simpson, G. B., \& Foster, M. R. (1986). Lexical ambiguity and children's word recognition. Developmental Psychology, 22(2), 147-154.

Squire, L. R., \& Kandel, E. R. (2003). Memória: da mente às moléculas. Porto Alegre: Artmed.

Tivarus, M. E., Ibinson, J. W., Hillier, A., Schmalbrock, P., \& Beversdorf, D.Q. (2006). An fMRI study of semantic priming: modulation of brain activity by varying semantic distances. Cognitive and Behavioral Neurology, 19(4), 194201.

Turkeltaub, P. E., Eickhoff, S. B., Laird, A. R., Fox, M., Wiener, M., \& Fox, P. (2012). Minimizing within-experiment and within-group effects in activation likelihood estimation meta-analyses. Human Brain Mapping, 33(1), 1-13. doi: 10.1002/hbm. 21186

Valdés, B., Catena, A., \& Marí-Beffa, P. (2005). Automatic and controlled semantic processing: a masked prime-task effect. Consciousness and Cognition, 14(2), 278-295.

Verfaellie, M., \& Keane, M. M. (1997). The neural basis of aware and unaware forms of memory. Seminars in Neurology, 17(2), 153-161.

Wible, C. G., Han, S. D., Spencer, M. H., Kubicki, M., Niznikiewicz, M. H., Jolesz, F. A., ... Nestor, P. (2006). Connectivity among semantic associates: an fMRI study of semantic priming. Brain and Language, 97(3), 294-305.

Recebido em: 22/03/2018 Primeira decisão editorial em: 13/07/2018 Aceito em: $24 / 08 / 2018$ 